independent risk factor for invasive aspergillosis and zygomycosis in patients with hematologic malignancy. Infect Control 1987:8:71-75

45. Sherertz RJ, Belani A, Kramer BS, et al. Impact of air filtration on nosocomial Aspergillus infections. Unique risk of bone marrow transplant recipients. Am J Med 1987;83:709-718.

46. Rhame FS. Prevention of nosocomial aspergillosis. J Hosp Infect 1991;18(suppl A) :466-472.

47. Rhame FS, Streifel AJ, Kersey JH Jr, et al. Extrinsic risk factors for pneumonia in the patient at high risk of infection. Am $J M e d$ 1984;76:42-52.

48. Brachman PS. Nosocomial infection-airborne or not? In: Brachman PS, Eickhoff TC, eds. In: Proceedings of the International Conference on Nosocomial Infections. Chicago, IL: American Hospital Association; 1971:189-192.

49. Kundsin RB. Documentation of airborne infection during sur- gery. Ann NYAcad Sci 1980:353:255-261.

50. Ayliffe GA. Role of the environment of the operating suite in surgical wound infection. Rev Infect Dis 1991;13(suppl):S800S804.

51. Haley RW, Tenney JH, Lindsey JO II, et al. How frequent are outbreaks of nosocomial infection in community hospitals? Infect Control 1985;6:233-236.

52. Wenzel RP, Thompson RL, Landry SM, et al. Hospital acquired infections in intensive care unit patients: an overview with emphasis on epidemics. Infect Control 1983;4:371-375.

53. Jarvis WR. Nosocomial outbreaks: the Centers for Disease Control's Hospital Infections Program experience, 1980-1990. Am J Med 1991;91 (suppl 3B):101S-106S.

54. Eickhoff TC. Microbiological sampling: hospitals. JAHA. 1970;44:86-87.

\title{
Whirlpool Bath Source of Outbreak of Legionnaires' Disease Aboard Cruise Ship
}

\section{by Gina Pugliese, RN, MS Medical News Editor}

As of August 10, 1994, a total of 14 passengers aboard the cruise ship Horizon had Legionnaires' disease (LD) confirmed by either sputum culture, detection of antigens of Legionella pneumophila serogroup 1 (LP,) in urine by radioimmunoassay, or fourfold rise in antibody titers between acute- and convalescent-phase serum specimens. Under investigation are 28 other passengers with pneumonia that occurred within 2 weeks after sailing aboard the cruise ship. Cases have occurred from separate week-long cruises between A pril 30 and July 9, 1994.

A case-control study revealed a strong association between exposure to whirlpool baths and illness. Cultures taken from a sand filter, used for recirculation of whirlpool water, yielded an isolate of $\mathrm{LP}_{1}$; this isolate and the clinical isolate had matching monoclonal antibody subtyping patterns. Various interventions were completed, including hyperchlorination of the ship's pota- ble water supply, removal of the whirlpool filters, and discontinuation of the whirlpool baths.

Additional recommendations to reduce the risk of transmission from whirlpool baths aboard cruise ships will be the subject of a special meeting scheduled to be held this fall. Information about the meeting is available from CDC's National Center for Environmental Health: (404) 488-7093.

FROM: Update: outbreak of Legionnaires' disease associated with a cruise ship. MMWR 1994;43(31):574-575. 